\title{
The clinical and anthropometric profile of undernourished children aged under 5 admitted to Nyangabgwe Referral Hospital in Botswana
}

\author{
A Madondo, U E MacIntyre, B Ntuli \\ Department of Public Health, University of Limpopo (Medunsa Campus), North-West \\ A Madondo, BSc, MPH \\ B Ntuli, MSW, MPH
}

Department of Human Nutrition, University of Pretoria

$\mathrm{U}$ E MacIntyre, $\mathrm{PhD}, \mathrm{RD}$ (SA)

Corresponding author: A Madondo (andymadondo@yahoo.com)

\begin{abstract}
Background. Although Botswana is a middle-income country, undernutrition among children younger than 5 years of age is still seen in various parts of the country. There is little information on the clinical and anthropometric profile of undernourished children in this age group admitted to hospitals in Francistown, Botswana.

Purpose. To determine the clinical profile and the severity of anthropometric failure of undernourished children aged under 5 admitted to Nyangabgwe Referral Hospital in Francistown.

Method. Data were collected from 113 caregiver-child pairs using a researcher-administered questionnaire targeting caregivers together with the children's hospital records. The children's anthropometric measurements were taken. Data were analysed using the WHO Anthro 2006 software and Stata 10. Proportions were then calculated.

Results. The median age of the children was 14 months and 55\% were boys. The majority of the caregivers were single, younger than 30 years and lived in rural villages. The most common symptoms on admission were oedema (50\%) and coughing (35\%). Ten per cent of the children were HIV-infected and the HIV status of half the children was unknown. The majority (87\%) did not present with secondary diagnoses. Severe wasting $(<-3$ standard deviations (SD)) $(73 \%)$ was found in all age groups. Stunting $(<-2 \mathrm{SD})$ was prevalent in $68 \%$ of the boys, and $95 \%$ of the children were severely underweight $(<-3 \mathrm{SD})$.

Conclusion. Oedematous undernutrition was common and $73 \%$ of the children presented with severe wasting ( $<-3 \mathrm{SD})$. In order to prevent severe forms of undernutrition, avoid the necessity for complicated care and improve the chances of survival, health education to caregivers on various forms of undernutrition is crucial.
\end{abstract}

S Afr J CH 2012;6(4):123-127. DOI:10.7196/SAJCH.450

Despite awareness about the dire impact of malnutrition on health and the availability of health and nutrition interventions, malnutrition continues to be one of the leading causes of morbidity and mortality worldwide, particularly in developing countries. Globally it has been estimated that stunting, severe wasting and intra-uterine growth restriction together accounted for 2.2 million deaths of children aged under $5 .{ }^{1}$ In developing countries the prevalence of malnutrition is high, with 1 out of 3 preschool children affected. ${ }^{2}$

Underlying causes of malnutrition as described in the United Nations International Children's Emergency Fund framework on child malnutrition include environmental, economic and sociopolitical factors, with poverty playing a major role. ${ }^{3}$

Consequences of malnutrition include shorter adult height, less schooling and reduced economic productivity, and for women offspring of lower birth weight. ${ }^{1}$ Furthermore, the risks of developing overweight, obesity, diabetes and hypertension are increased among adults who suffered from undernutrition during early childhood. ${ }^{4}$ Botswana is one of the most economically stable countries in southern Africa and subscribes to initiatives such as the United Nations Millennium Development Goals (MDGs), one of the aims of which is to reduce the number of people suffering from hunger by $50 \%$ by 2015 . However, despite this, Botswana faces child malnutrition problems. In 2007, 13\% of children aged 5 years and under were malnourished, with $26 \%$ stunted, $7.2 \%$ wasted and $13.5 \%$ underweight. ${ }^{5}$ Malnutrition refers to the various forms of undernutrition, which are stunting, wasting and underweight.

Various studies on child malnutrition on the African continent have shown that demographic, socio-economic and clinical profiles of malnourished children differ from one region to the next. Characteristics that were found to contribute to child malnutrition in the different regions ranged from the age of the child or the caregiver, family size and income and the caregiver's education to underlying clinical conditions. ${ }^{6-9}$

The aim of this study was therefore to determine the clinical profile and the severity of anthropometric failure of undernourished children aged under 5 admitted to Nyangabgwe Referral Hospital in Francistown, Botswana. 


\section{Patients and methods}

The study used a quantitative approach and a descriptive design to collect sociodemographic data from the caregivers and clinical and anthropometric data from the children admitted to the paediatric wards at Nyangabgwe Referral Hospital, the only tertiary hospital in Francistown.

\section{Patients}

The study population comprised caregiver-child pairs with an admission diagnosis of malnutrition, protein energy malnutrition or oedematous malnutrition admitted during the period February - August 2011. A sample size calculation was done using Epi Info 3.5.1 (2008). The desired sample size was 96 caregiver-child pairs. After written informed consent had been obtained, caregivers with malnourished children aged between 6 and 60 months who had been taking care of the child for at least 6 months were enrolled into the study. Critically ill malnourished children and children too weak to participate in anthropometric measurements were excluded from the study sample.

\section{Data collection}

The caregivers' socio-demographic data were obtained in an interview using a structured questionnaire developed by the researcher (AM). The child's clinical signs and symptoms on admission were obtained from the medical record.

Anthropometric measurements Weight. Weight was recorded in kilograms to the nearest $0.1 \mathrm{~kg}$ using a standardised $25 \mathrm{~kg}$ Salter spring scale, Model 235 6S (Salter Industrial Measurements Ltd, West Bromwich, UK). The children were weighed in their underclothes, and infants were weighed naked in an upright freehanging position.

Length/height. The length of children younger than 24 months was measured using a measuring board (Shorr Productions, Md, USA) to the nearest $0.1 \mathrm{~cm}$. The heights of children aged 24 months and older were measured using a perpendicular Seca Model 220 stadiometer (Seca Ltd, Birmingham, UK), with the child standing upright without shoes and facing forwards. Height was recorded in centimetres to the nearest $0.1 \mathrm{~cm}$. Children's measurements were recorded on average 4 days after admission.

\section{Ethical considerations}

Ethical clearance was obtained from the Medunsa Research Ethics Committee (MREC), Medunsa campus, University of Limpopo; the Research Ethics Committee of the Botswana Ministry of Health; and the Nyangabgwe Referral Hospital's Research Ethics Committee.

The researcher (AM) and the research assistant explained the study to the caregivers in the local language. The voluntary nature of the study and the guarantee of participants' privacy were also explained. All caregivers willing to participate in the study signed an informed consent form. The caregivers remained free to withdraw from the study at any time without consequences. All information was kept confidential.

\section{Statistical analysis}

Socio-demographic data were entered into a Microsoft Excel 2007 spreadsheet. The child's anthropometric data, date of birth, age and gender were entered into the WHO Anthro v2.0.2 (2006) programme for the calculation of $\mathrm{z}$-scores for weight-for-age (WAZ), weight-for-length/height (WHZ) and length/height-for-age (HAZ). All data were imported to STATA 10 (StataCorp 2007) for statistical analysis.

Underweight, wasting and stunting were identified by $z$-scores below -2 for WAZ, WHZ and HAZ, respectively. ${ }^{10}$ Severe underweight, wasting and stunting were identified by z-scores of less than -3. Frequencies for gender, marital status, income, education and occupation of the caregiver and the clinical profile data and anthropometric status of the child were calculated.

\section{Results}

The sample comprised 113 caregiverchild pairs. The socio-demographic characteristics of the caregivers and the children are summarised in Table 1 . The majority of caregivers were the child's mother (89.4\%), single (79.7\%) and younger than 30 years $(74.3 \%)$, had some formal education (91.1\%), and came from surrounding villages (70.8\%). Most households (73.5\%) had 7 or fewer members. The monthly income of almost all (96.5\%) was less than 2000 pula/month (US\$250), while $57.5 \%$ of the caregivers survived on less than 500 pula a month (i.e. approximately US $\$ 2$ per day).

Of the children, 62 (54.9\%) were boys (mean age 17.2 months, standard deviation (SD) 9.5 months). For both genders, the largest proportion of children was aged between 6 and 23 months $(49.6 \%$ and $38.1 \%$ for boys and girls, respectively). The median age for both boys and girls was 14 months. The HIV status of 56 (49.6\%)
Table 1. Socio-demographic characteristics of caregivers and children

\begin{tabular}{lll}
\hline Characteristic & $\begin{array}{l}\text { Frequency } \\
(\boldsymbol{N = 1 1 3 )}\end{array}$ & \% \\
\hline Caregivers & & \\
Age (years) & & \\
$15-20$ & 17 & 15 \\
$21-30$ & 67 & 59.3 \\
$31-40$ & 21 & 18.6 \\
$>40$ & 8 & 7.1
\end{tabular}

Relationship to child

Mother

Father

Grandmother

Sister

Marital status

Married

Single

Cohabiting

Widowed

Level of education

Primary

Secondary

Tertiary

No formal education

No. of individuals in household

$\leq 4$

Place of residence

Urban

Village/rural

Occupation

Employed

Self-employed

Pensioner

Household monthly income (pula)

$$
<500
$$

$100-1999$

\section{Children}

Gender

Boys

Girls

Age (months)

$6-11$ 
of the children was unknown, $12(10.6 \%)$ were HIV-infected, and 45 (39.8\%) were HIV- negative. Diagnoses of pneumonia and tuberculosis (TB) secondary to malnutrition were recorded for 9 $(8.0 \%)$ and $3(2.7 \%)$ of the children, respectively (Table 2). Most children $(86.7 \%)$ did not present with a secondary diagnosis.

Table 3 sets out the signs and symptoms of the children on admission, according to age group. Oedema and coughing were the most common symptoms on admission to hospital (49.6\% and 35.4\%, respectively). The 12 - 23-month-old children presented with most (85.9\%) signs and symptoms on admission. Diarrhoea (43.3\%) and swollen limbs (40.7\%) were the most commonly reported conditions in the 6 months prior to admission. Coughing and vomiting were also common $(30.9 \%$ and $24.8 \%$, respectively).

Figs 1 - 3 show the percentage distribution of the WHZ, HAZ and WAZ scores among the children according to age group and gender.

Severe wasting $(<-3$ standard deviations (SD)) was more common than moderate wasting (between -3 and -2.1 SD) (Fig. 1). Among the boys in the age group $6-11$ months, $75.0 \%$ appeared severely wasted compared with $69.2 \%$ of the females.

Fig. 2 indicates the distribution of stunting among the children according to age group. Stunting was least common in the age group 6 - 11 months. In general, stunting and severe stunting were not common across all age groups. There was, however, a significant association between gender and severity of stunting $(p<0.05)$.

Fig. 3 indicates the distribution of underweight children according to age group. The prevalence of severe underweight $(<-3 \mathrm{SD})$ was high in the age groups $12-23$ months $(82.5 \%$ of boys and $82.1 \%$ of girls) and $6-11$ months ( $75.0 \%$ of boys and $69.2 \%$ of girls) for all the children.

\section{Discussion}

Our study describes the socio-demographic, clinical and anthropometric profiles of children diagnosed as undernourished and admitted to Nyangabgwe Referral Hospital. Although the findings cannot accurately represent the extent of undernutrition in Botswana, they do provide a socio-demographic and clinical picture of severe undernutrition of under-5-year-olds. The sociodemographic background reflects that of undernourished children reported from Botswana ${ }^{7}$ and other developing countries in that the majority of caregivers were single mothers $(78 \%)^{7,11}$ from lowincome households (96\%), ${ }^{12-14}$ large families ( $>5$ members) $(73 \%)^{12,14}$ and rural areas (71\%). ${ }^{15}$ In contrast to studies by Chakraborty et al. ${ }^{16}$ Turyashemererwa et al. ${ }^{17}$ and Janevic et al. ${ }^{13}$ which reported an association between poor educational background of the caregiver and child undernutrition, most caregivers (65.3\%) in our study had attained a higher level of education (secondary/tertiary education). At a populationlevel, the South African National Food Consumption Survey ${ }^{18}$ found that nationally the prevalence of undernutrition decreased significantly with increasing maternal education levels. Owor et al., ${ }^{19}$ however, found that a formal education did not appear to influence the nutritional status of children. The finding in our study that the majority of undernourished children came from rural villages differs from results of a study in Uganda showing that living in an urban setting was associated with malnutrition. ${ }^{20}$ Our finding could be attributed to the fact that most families in the villages were large and experienced general food shortages. Many villagers relied on government food handouts to survive, as large tracts of land could not be developed to increase the availability of food. ${ }^{4}$

Our results show that $57.5 \%$ of the caregivers survived on less than 500 pula a month (equivalent to US\$65.00). Comparison with findings from the Botswana Central Statistics Office (2004) showed that the number of people living below US $\$ 1.00$ per day increased from $19.9 \%$ in $1993 / 94$ to $23.4 \%$ in $2002 / 03$. Poverty levels have therefore increased during this period and this is most likely to have a negative impact on food availability at family level.

Studies by Olwedo et al. ${ }^{20}$ in Uganda, Emina et al. ${ }^{9}$ in the Democratic Republic of Congo and Irena et al. ${ }^{21}$ in Zambia have suggested that undernutrition is more prevalent among boys than among girls. Mahgoub and Adam, ${ }^{22}$ after reviewing medical records of 1097 children admitted to hospital in Eastern Sudan, concluded that there was no difference in the case fatality rate between boys and girls. Likewise, our

Table 2. Medical status of children on admission $(N=113)$

\begin{tabular}{|c|c|c|c|c|c|c|c|c|c|}
\hline \multicolumn{5}{|c|}{ HIV status of the child } & \multicolumn{5}{|c|}{ Secondary diagnoses } \\
\hline $\begin{array}{l}\text { Age group } \\
\text { (months) }\end{array}$ & $\begin{array}{l}\text { HIV- } \\
n(\%)\end{array}$ & $\begin{array}{l}\text { HIV+ } \\
n(\%)\end{array}$ & $\begin{array}{l}\text { Unknown } \\
n(\%)\end{array}$ & Total & $\begin{array}{l}\text { Pneumonia } \\
n(\%)\end{array}$ & $\begin{array}{l}\text { TB } \\
n(\%)\end{array}$ & $\begin{array}{l}\text { Other } \\
n(\%)\end{array}$ & $\begin{array}{l}\text { None } \\
n(\%)\end{array}$ & Total \\
\hline $6-11$ & $11(33.3)$ & $6(18.2)$ & $16(48.5)$ & 33 & $5(15.6)$ & $2(6.3)$ & $1(3.1)$ & $25(75.7)$ & $33(29.2)$ \\
\hline $12-23$ & $30(45.5)$ & $2(3.0)$ & $34(51.5)$ & 66 & $1(1.5)$ & $1(1.5)$ & $1(1.5)$ & $63(95.5)$ & $66(58.4)$ \\
\hline $24-35$ & $3(42.9)$ & $1(14.3)$ & $3(42.9)$ & 7 & $1(1.4)$ & 0 & 0 & $6(85.7)$ & $7(6.2)$ \\
\hline $36-60^{*}$ & $1(14.3)$ & $3(42.9)$ & $3(42.9)$ & 7 & $2(28.6)$ & 0 & $1(14.3)$ & $4(57.1)$ & $7(6.2)$ \\
\hline Total & $45(39.8)$ & $12(10.6)$ & $56(49.6)$ & 113 & $9(8.0)$ & $3(2.7)$ & $3(2.7)$ & $98(86.7)$ & 113 \\
\hline
\end{tabular}

Age groups 36 - 47 and 48 - 60 months combined owing to the small number of children in these groups.

Table 3. Signs and symptoms of the children on admission $(N=113)$

\begin{tabular}{|c|c|c|c|c|c|c|c|c|}
\hline $\begin{array}{l}\text { Age group } \\
\text { (months) }\end{array}$ & $\begin{array}{l}\text { Oedema } \\
n(\%)\end{array}$ & $\begin{array}{l}\text { Fever } \\
n(\%)\end{array}$ & $\begin{array}{l}\text { Vomiting } \\
n(\%)\end{array}$ & $\begin{array}{l}\text { Diarrhoea } \\
n(\%)\end{array}$ & $\begin{array}{l}\text { Coughing } \\
n(\%)\end{array}$ & $\begin{array}{l}\text { Anaemia } \\
n(\%)\end{array}$ & $\begin{array}{l}\text { Peeling skin } \\
n(\%)\end{array}$ & $\begin{array}{l}\text { Total signs } \\
\text { and symptoms }\end{array}$ \\
\hline $6-11$ & $13(39.4)$ & $1(3.0)$ & $4(12.0)$ & $6(18.2)$ & $11(33.3)$ & $5(15.2)$ & $2(6.0)$ & $42(37.1)$ \\
\hline $12-23$ & $36(54.5)$ & $1(1.5)$ & $15(22.7)$ & $17(25.8)$ & $24(36.4)$ & $0(0.0)$ & $4(6.1)$ & $97(85.8)$ \\
\hline $24-35$ & $5(71.4)$ & $0(0.0)$ & $2(28.6)$ & $2(28.6)$ & $2(28.6)$ & $2(28.6)$ & $0(0.0)$ & $13(11.5)$ \\
\hline $36-60^{*}$ & $2(28.6)$ & $0(0.0)$ & $2(28.6)$ & $0(0.0)$ & $3(43.0)$ & $1(14.3)$ & $0(0.0)$ & $8(7.1)$ \\
\hline Total & $56(49.6)$ & $2(1.8)$ & $23(20.4)$ & $25(22.1)$ & $40(35.4)$ & $8(7.1)$ & $6(5.3)$ & $160(100)$ \\
\hline
\end{tabular}

Age groups 36 - 47 and 48 - 60 months combined owing to the small number of children in these groups. 
study showed no difference in the proportions of boys and girls admitted for undernutrition, or in the severity of underweight or wasting between males and females. There was, however, a significant association between gender and severity of stunting $(p<0.05)$.

The finding that the HIV status of half the children in our study was unknown is cause for concern. Prevalences of HIV infection as high as $51 \%$ have been reported among malnourished patients in both hospital ${ }^{23}$ and community ${ }^{24}$ settings. With a national HIV prevalence of $6.3 \%$ for children aged $1.5-4$ years in Botswana, ${ }^{25}$ there is a strong possibility that a greater proportion of the children in our study were HIV-infected. Failure to identify HIV infection in undernourished patients may increase morbidity, mortality and hospital stay. The risk of mortality and of concurrent infections such as diarrhoea and pneumonia is increased in HIV-infected undernourished children, ${ }^{21,26}$ and these children therefore require close monitoring and special care during hospitalisation. A cross-sectional study by Mda et al..$^{26}$ reported the appetite of hospitalised HIVinfected children to be $26 \%$ poorer than that of uninfected children. Furthermore, the appetite, morbidity and recovery of HIVinfected children were improved by multimicronutrient supplementation. ${ }^{27}$

Oedema was present in $49.6 \%$ of children on admission. The presence of oedema indicates severe undernutrition, but may mask the extent of weight loss. Other presenting signs and symptoms included coughing (35.4\%), diarrhoea (22.1\%) and vomiting (20.4\%). Diarrhoea is known to be a major factor contributing to undernutrition. ${ }^{28}$ Children with severe acute malnutrition and diarrhoea on admission to a Zambian hospital were found to have over twice the odds of mortality compared with children without diarrhoea. ${ }^{21}$

Wasting (WHZ score <-2SD) was present in $93.8 \%$ of children and severe wasting (WHZ score $<-3 \mathrm{SD}$ ) in $72.5 \%$. Wasting is indicative of acute undernutrition resulting from a combination of factors including illness, reduced food intake and reductions in food availability. Severe acute malnutrition (WHZ score $<-3 \mathrm{SD}$ and oedema) is associated with an increased risk of mortality and demands immediate attention..$^{29} \mathrm{~A}$ high prevalence of wasting indicates late recognition of weight loss, possibly because of the masking of weight loss by oedema. In Botswana any child seen at a clinic with an SD score of -2 and below is referred to hospital for management. This SD value alone can be misleading, as children with moderate oedematous malnutrition may not be easily recognised at clinics by nurses or other health care assistants who are responsible for monitoring child growth, as they lack the necessary health assessment skills.

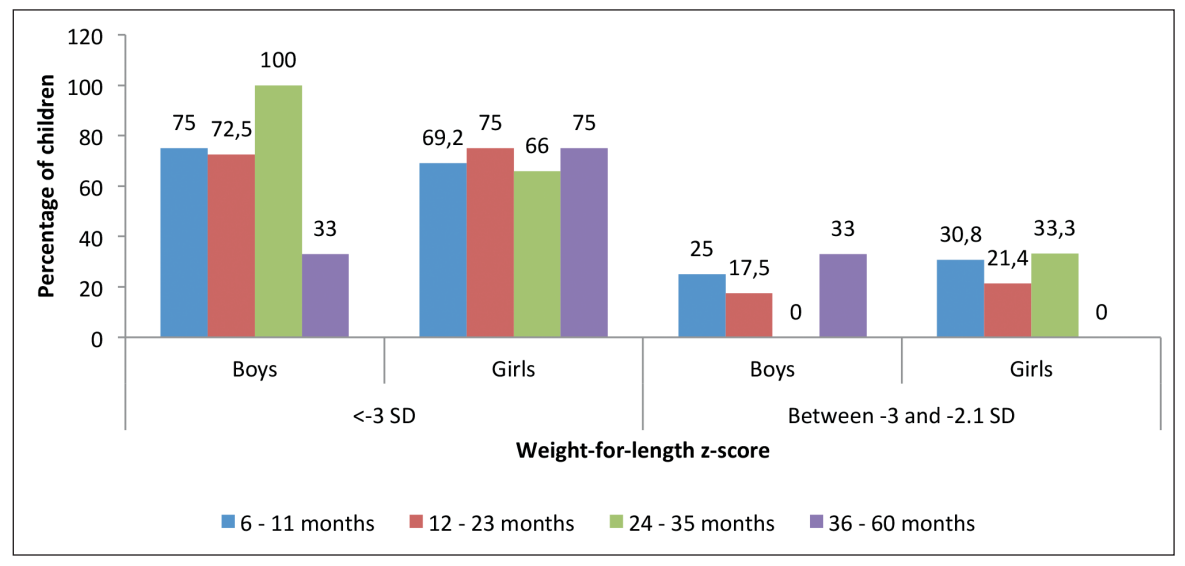

Fig. 1. Frequency distribution of $W H Z z$-scores of the children, according to age group.

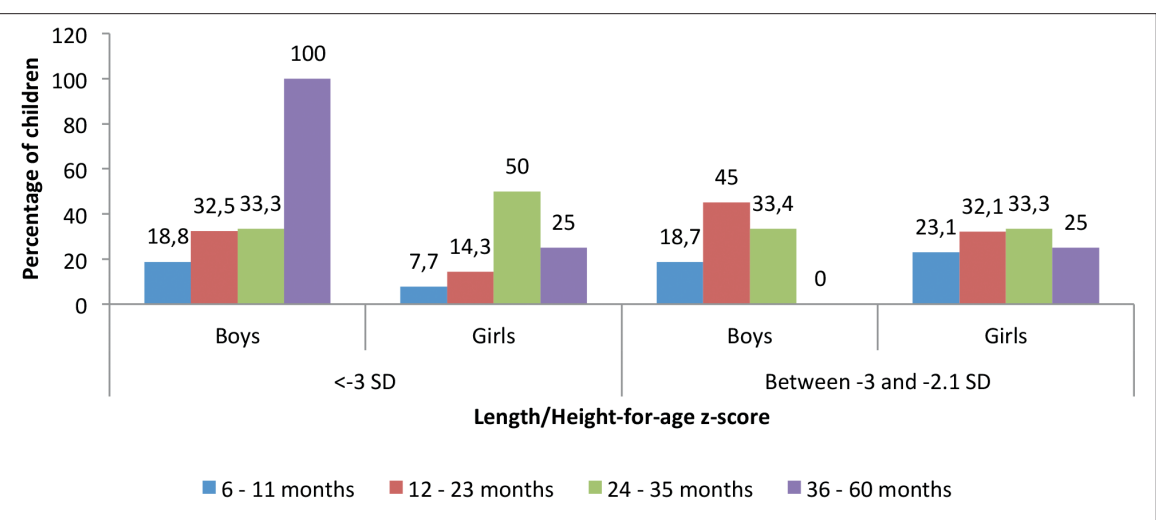

Fig. 2. Frequency distribution of $H A Z z$-scores of the children, according to age group.

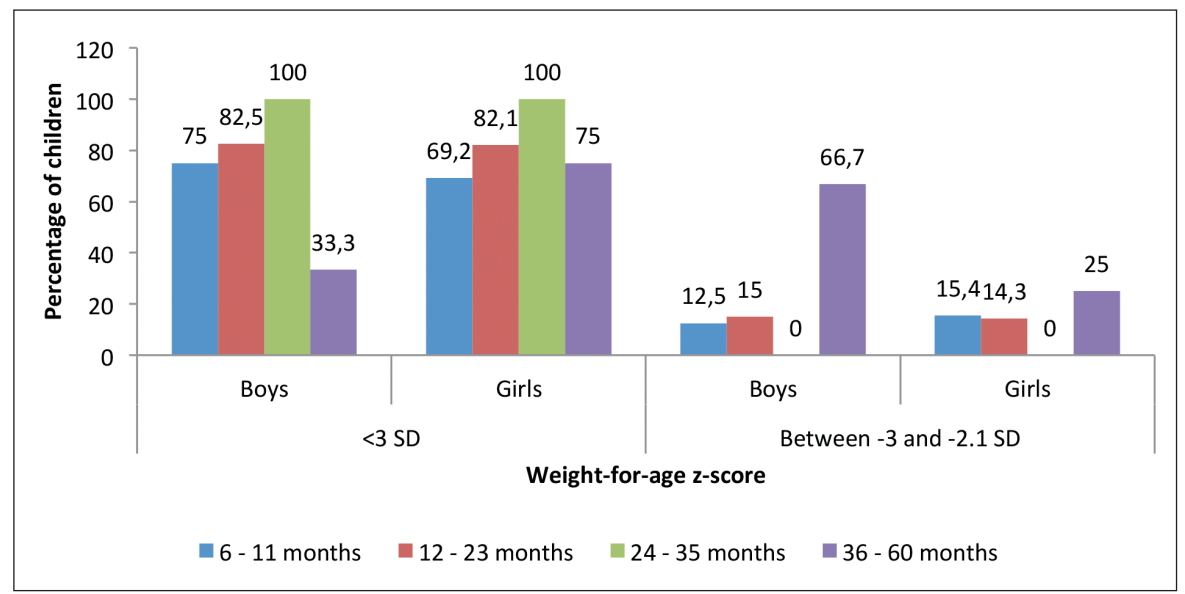

Fig. 3. Frequency distribution of $W A Z z$-scores of the children, according to age group.

Stunting (HAZ score <-2 SD), a sign of chronic undernutrition, was present in $67.7 \%$ of the boys and $47.1 \%$ of the girls $(p<0.05)$. Higher prevalences of stunting among boys than girls have also been reported from Indonesia ${ }^{30}$ and South Africa. ${ }^{31}$ At population level in South Africa the prevalence of stunting decreased with age from $25.5 \%$ among children aged $1-3$ years to $21 \%$ in children aged $4-6$ years and $13 \%$ in children aged $7-9$ years. ${ }^{18}$

Severe underweight (WAZ score <-3 SD), a measure of both chronic and acute malnutrition, was present in $79.6 \%$ of children. Underweight represents an acute episode of undernutrition resulting from illness or impaired food intake, superimposed on chronic undernutrition usually associated with poverty and food insecurity. A national study by Labadarios $e t$ al. ${ }^{18}$ in South Africa found that less than $1.5 \%$ of the children were underweight; however, this study was at national level and not at hospital level. The $50 \%$ prevalence of oedematous malnutrition in this study presents a challenge to determining the extent of underweight in the children, given that oedema masks weight loss. Since being underweight points to both chronic and acute malnutrition in children, this study shows that undernutrition among children needs to be addressed with respect to current as well as long-term sustainable interventions. 
Anthropometric measurements were taken on average 4 days after admission, so the severity of malnutrition on admission may have been worse than our figures indicate. The results of this study cannot be generalised to the whole population, as the study participants were recruited in a hospital setting. Only undernourished children admitted to hospital were considered; those at home, perhaps with no money to go to the clinic, were not included. Data on caregiver feeding practice were not collected, despite the fact that this plays a major role in children's nutritional health.

Child malnutrition remains a challenge in most poor and developing countries. With $72.5 \%$ of children severely wasted and $79.6 \%$ severely underweight, our findings highlight the severity of malnutrition of children admitted to a Botswana hospital when compared, for example, with results of a study of children in health facilities by Nnyepi, ${ }^{32}$ where $11.3 \%$ of children were estimated to be underweight and $3.9 \%$ to be wasted. This study has shown that although a number of common factors contribute to undernutrition of children, each region has its own unique features that play a role. Proper health education could prevent severe forms of undernutrition, avoid the necessity for complicated care, and improve chances of survival. Undernutrition is a result of multidimensional characteristics of the caregiver and the clinical profile of a child, which may vary from one region to the next. Finding characteristics specific to the locality that can be associated with undernutrition represents a basic step in the fight against undernutrition.

Acknowledgement. This study was funded by the Directorate General for Development Cooperation (DGDC) through the Flemish Interuniversity Council (VLIR-OUS).

\section{References}

1. Black RE, Allen HL, Bhutta ZA, et al. Maternal and child undernutrition: global and regional exposures and health consequences. Lancet 2008;371:243-260. [http://dx.doi. org/10.1016/S0140-6736(07)61690-0]

2. United Nations Sub-Committee on Nutrition. 5th Report on the World Nutrition Situation: Nutrition for Improved Outcomes. 2004. http://www.unsystem.org/scn/ Publications/AnnualMeeting/SCN3/SCN5Report.pdf (accessed 20 March 2012).

3. United Nations International Children's Emergency Fund (UNICEF). Strategy for Improved Nutrition of Children and Women in Developing Countries. New York: UNICEF, 1990.

4. Martins VJB, Florêncio TMMT, Grillo LP, et al. Long-lasting effects of undernutrition. Int J Environ Res Public Health 2011;8:1817-1846.

5. United Nations (UN). Botswana Millennium Development Goals 2010: Status Report. Gaborone, Botswana: UN House, UN Office Botswana, 2010.

6. Smith CL, Haddad L. Explaining child malnutrition in developing countries: a cross-sectional analysis. International Food Policy Research Institute. 2000. http:// www.ifpri.org/pubs/abstracts/111/rr111.pdf (accessed 22 June 2009).

7. Mahgoub OES, Nnyepi M, Bandeke T. Factors affecting prevalence of malnutrition among children under three years of age in Botswana. African Journal of Food Agriculture Nutrition and Development 2006;6(1):1-9.

8. Faber M, Wenhold F. Nutrition in contemporary South Africa. Water SA 2007;33(3):398-400.

9. Emina JB, Kandala N, Inungu J. The effect of maternal education on child nutritional status in the Democratic Republic of the Congo. Nairobi, Kenya: African Population and Health Research Center, 2009.

10. Cogill B. Anthropometric Indicators Measurement Guide. Food and Nutrition Technical Assistance Project 2003. Washington, DC: Academy for Educational Development, 2003.

11. Adeladza TA. The influence of socio-economic and nutritional characteristics on child growth in Kwale District of Kenya. African Journal of Food Agriculture, Nutrition and Development 2009;9(7):1570-1590.

12. Amsala S, Tigabu Z. Risk factors for severe acute malnutrition in children under the age of five: A case-control study. Ethiopian Journal of Health Development 2008;22(1):21-25.
13. Janevic T, Petrovic O, Bjelic I, Kubera A. Risk factors for childhood malnutrition in Roma settlements in Serbia. BMC Public Health 2010;10:624-627. [http://dx.doi. org/10.1186/1471-2458-10-509]

14. Abubaker A, Holding P, Mwangome M, Maitland K. Maternal perceptions of factors contributing to severe under-nutrition among children in a rural African setting. Rural and Remote Health 2011;11:1423-1434. http//rrh.org.au (accessed 23 March 2012).

15. Khatab K. Childhood malnutrition in Eygpt using geoadditive and latent variable models. Am J Trop Med Hyg 2010;82(4):653-663. [http://dx.doi.org/10.4269/ ajtmh.2010.09-0501]

16. Chakraborty S, Gupta SB, Chaturvedi B, Chakraborty SK. A study of protein energy malnutrition in a rural population of Jhansi District (UP). Indian Journal of Community Medicine 2006;31(4):291-292.

17. Turyashemererwa FM, Kikafunda JK, Agaba E. Prevalence of early childhood malnutrition and influencing factors in peri-urban areas of Kabarole District, Western Uganda. African Journal of Food Agriculture, Nutrition and Development 2009;9(4):974-989.

18. Labadarios D, Steyn NP, Maunder E, et al. The national food consumption survey (NFCS): South Africa, 1999. Public Health Nutr 2005;8(5):533-543.

19. Owor M,Tumwine KJ, Kikafunda JK. Socio-economic risk factors for severe protein energy malnutrition among children in Mulago Hospital, Kampala. East Afr Med J 2000;77(9):471-475.

20. Olwedo MA, Mworozi E, Bachou H, Orach GC. Factors associated with malnutrition among children in internally displaced person's camps, northern Uganda. Afr Health Sci 2008;(8):244-252.

21. Irena AH, Mwambazi M, Mulenga V. Diarrhea is a major killer of children with severe acute malnutrition admitted to an inpatient set-up in Lusaka, Zambia. Nutr J 2011;10:110-115. http://www.nutritionj.com/content/10/1/110 (accessed 23 March 2012). [http://dx.doi.org/10.1186/1475-2891-10-110]

22. Mahgoub HM, Adam I. Morbidity and mortality of severe malnutrition among Sudanese children in New Halfa Hospital, Eastern Sudan. Trans R Soc Trop Med Hyg 2012;106:66-68. [http://dx.doi.org/10.1016/j.trstmh.2011.09.003]

23. De Maayer T, Saloojee H. Clinical outcomes of severe malnutrition in a high tuberculosis and HIV setting. Arch Dis Child 2011;96(6):560-564.

24. Magadi MA. Household and community HIV/AIDS status and child malnutrition in sub-Saharan Africa: evidence from the demographic and health surveys. Soc Sci Med 2011;73(3):436-446.

25. UNICEF. A world fit for children: Mid decade review. Botswana progress report. 2007. http://www.unicef.org/worldfitforchildren/files/Botswana_WFFC5_Report. pdf (accessed 30 March 2012).

26. Mda S, van Raaij JMA, MacIntyre UE, de Villiers FPR, Kok FJ. Duration of hospitalization and appetite of HIV-infected South African children. Maternal and Child Nutrition 2011; 7: 175-187. [http://dx.doi.org/10.1111/j.17408709.2009.00228.x.]

27. Mda S, van Raaij JMA, de Villiers FPR, MacIntyre UE, Kok FJ. Short-term micronutrient supplementation reduces the duration of pneumonia and diarrheal episodes in HIV-infected children. J Nutr 2010;140:969-974.

28. Saloojee H, Maayer De T, Garenne LM, Kahn K. What's new? Investigating risk factors for severe childhood malnutrition in a high HIV prevalence South African setting. Scand J Public Health Suppl 2007;69:96-106.

29. Tanner-Grobler C. Nutrition and Food Security Early Warning in Niger: Recommendations for the Famine Early Warning Systems Network and Partners to Monitor and Address the Information Gap in Niger 2006. Washington, DC: USAID, 2006.

30. Ramil R, Agho EK, Inder JK, Bowe JS, Jacobs J, Dibley JM. Prevalence and risk factors for stunting and severe stunting among under-fives in North Maluku province of Indonesia. BMC Pediatr 2009;9:64. http://www.ncbi.nlm.gov/pmc/ articles/PMC2765943/ (accessed 13 June 2011). [http://dx.doi.org/10.1186/14712431-9-64]

31. Zere E, McIntyre D. Inequities in under-five child malnutrition in South Africa. International Journal for Equity in Health 2003;2:7. http://www.equityhealthj. com/content/2/1/7 (accessed 14 June 2011). [http://dx.doi.org/10.1186/14759276-2-7]

32. Nnyepi M. Dietary and nutrition screening for children seeking curative care in health facilities in Botswana. African Journal of Food Agriculture Nutrition and Development 2006;6(2):1-16. 